\title{
On Ways of Developing Islands from the Perspective of Population and Islands' Special Features
}

\author{
Yangyang Chen, Fangjie He* \\ Zhejiang Ocean University, Zhoushan, China
}

*Corresponding Author: Fangjie He, Zhejiang Ocean University, Zhoushan, China

\begin{abstract}
At the 19th National Congress, it stressed that the efforts to build China into a maritime power should be accelerated. To build China into a maritime power, we must pay attention to island development. In China, the area of islands and their adjacent sea area accounts for 308.6 square kilometers, equivalently onethird of the land area and abounds in such marine resources as fishery, ports, scenery, oil, energy. Beyond that, there are $70 \%$ of islands that have freshwater and permanent residents. However, the exploitation of islands is extraordinarily insufficient as compared with developed countries.

Our research is carried out through literature collection, local population, and economic condition data collection, questionnaire survey to and in-depth individual interviews with the elderly and enterprise owners, and final data analysis. In the end, we thought out three solutions. Firstly, developing unique islands. Secondly, changing the erroneous opinions towards the old citizens, in other words, recognizing older people's self-worth. Thirdly, promoting the old citizens' contributions to economic development, including promoting the re-employment and enhancing the education level of the elderly. Finally, encouraging people everywhere to participate in island development via the Internet or any other means.
\end{abstract}

Keywords: Island economy, population problem, Characteristic Island

\section{INTRODUCTION}

\subsection{Background}

Between 2017 and 2018, the Gross Ocean Product reached 8.3 trillion yuan, with a year-on-year growth of $6.7 \%$, and the Chinese marine economy contributed nearly $10 \%$ to the national economy. Besides, the marine industry has been upgrading, and there is an excellent potential for the marine economy, which has become a new economic growth point. However, having multitudinous resourceful islands, China did not do well in developing its islands, which are playing a much weaker role in developing the marine economy as compared with the islands of some marine powers. Nonetheless, nowadays, there are splendid opportunities that accompany the boom of digital communication. Literature does suggest that broadband not only supports rural businesses' growth(Whitacre et al., 2014), but helps overcome challenges associated with rural areas incorporating the "isolation from markets, relatively less networking, support provision and the competition from external web-based providers" (Galloway et al., 2011, p255). Besides, we confidently hold that digital telecommunications can be applied to boost the island economy in many other respects.

Under such circumstances, it is of interest to us to explore how to develop islands significantly from a marine economy perspective and digital telecommunications perspective. What is more, this article prioritizes some of the development avenues, because we should adjust measures to local conditions and only when the island develops to some extent can its local government's tax revenue be increased significantly to support other relevant measures. So all in all, this thesis focuses on island development.

\subsection{The Current Research}

Though island development is vital without a doubt and to date, there is a growing body of literature that has studied island development, but there is a lack of theoretical and empirical research to understand the impact of population and islands' unique characteristics on island development. Here 
the islands' unique characteristics mainly refer to the problems that were generated on account of islands' ecological environment, geographic location. This study is an attempt to fill the gap.

\subsection{The Significance and Purpose of The Study}

The following two facts roughly indicate island development's significance. First, Islands and their adjacent sea area has bountiful marine resources. To transform the advantages of marine resources into real resources and develop the blue economy, we should develop islands. Second, the development of the island can promote the soundness of islands and surrounding waters' relative measures of ecological protection. Whereas improving ecological protection can, in turn, promotes sustainable economic development, therefore, a virtuous circle can be formed.

Given the importance of island development, our research is imperative, and we fully expected that we would achieve our targets: 1 . The local population quality will be improved, and the native will master many more technical skills; 2 . The local elderly will take an active part in economic development. 3. Tourism will be more prosperous, and the local industry will upgrade. 4. More people will participate in Taohua Island's development via the Internet or other means. 5. The countermeasures we proposed will be considered not only by Taohua Island, but also other similar islands for reference.

\subsection{Research Methods}

To realize our goals, we researched through methods of literature study, social investigation, and systematic analysis.

The social investigation was done in Taohua Island in Zhoushan, a city whose marine economy output value accounts for $67.6 \%$ of GDP, the highest ratio in China. As Taohua Island is an average island, its development methods can be suitable to a great many of other islands.

To be specific, the social investigation incorporates the questionnaire research, personal interviews, and the local government data acquisition, which is before the first two matters and helped us generally understood the local population situation and economic condition. Then during the questionnaire research, we investigated 950 old citizens and 30 owners of enterprises and have interviews with some of them.

\section{RESEARCH DESIGN}

\subsection{Research Objects}

The research objects of this paper are mostly the older residents (above 60) and the enterprises' owners of Taohua Island. The authors of this article have selected 50 older people and 30 enterprise owners from these research objects as samples.

\subsection{Research Issues}

We designed two questionnaires which are respectively targeted at the older citizens over the age of 60 and the enterprise owners.

The former chiefly covers the issues of the respondents' necessary information, which includes gender, age, and other information such as their educational backgrounds, work experiences, health conditions, income. Besides, there is an issue about whether the individual respondent has an intention to go back to work if he does not have employment now.

The latter one primarily incorporates the issues of the size of the entrepreneur's company, the nature of it, its attitude towards older citizens, and whether it will recruit older citizens. This questionnaire will also focus on the company's future visions and development strategy to see whether the company has excellent potential and will benefit the local economy a lot in the future.

\section{THE INFLUENCE FACTORS OF ISLAND DEVELOPMENT}

\subsection{Serious Aging Problem}

After gathering the Taohua Island, our investigation site's demographics, we found that the region's aging problem was very conspicuous. In 2017, China's ratio of the elderly in its population reached $17.3 \%$, and this region's ratio of that is far more than the national ratio. The following Figure 1 shows 
Taohua Island's demographic structure in 2017.

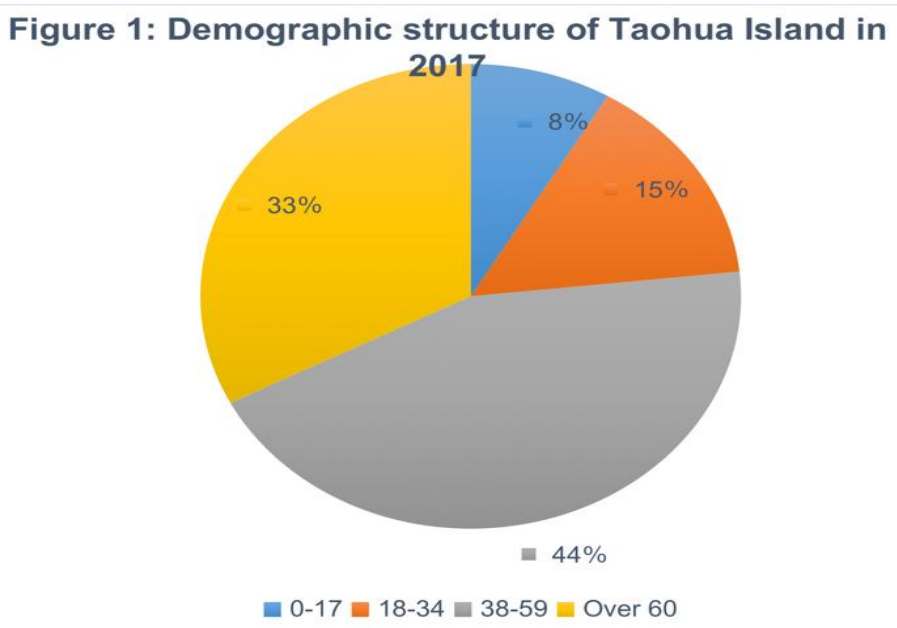

From the above table (Computed from the Local Government-held Data), it found that the elderly (over age 60) made up $32.5 \%$ of the population. In line with the international definition standards of an aging society, when a region's old people account for more than $10 \%$ of the population, this region enters the aging society. Hence, Taohua Island's aging problem is grievous. As its aging problem is also accompanied by a labor shortage, its economic development has been impeded markedly.

The push-pull theory may explain the origin of this serious aging problem. According to this theory, migration is the result of the interaction of push from former residence, pull from the area (s) of destination, and intervening obstacles. The following critical reasons offered are explained in these aspects.

Firstly, the Chinese government has advanced the reform of the household registration system. It provides system security and has incentivized many rural people to migrate to cities and towns.

Secondly, in islands, there are limited job opportunities, mainly including farming and fishing, and the job prospects are poor. Besides, in consequence of the decreased cultivated land, being engaged in agriculture is toilsome, and the earning of it is low. As for the fishing, the fishery resources have been reduced sharply, Taohua Island's marine fishery products have reduced gradually for the years that span from 2015 to 2017, and the deep-sea fishing is dangerous for the sailors whose fishing technique is weak, so the prospects of it do not look right. Beyond that, the scales of the island's enterprises are tiny, so they cannot absorb the massive labor forces.

Thirdly, there are scarce educational resources on the island, whereas the cities and towns have much more educational resources. Hence, young people can learn more knowledge and skills in cities. Besides that, they can make the acquaintance of many competent people who can help them in various aspects.

Fourthly, Taohua Island is lacking in infrastructure and recreational facilities, and making matters worse, the transport infrastructure is hard to improve, considering that the island is mountainous. Most young people feel that living under this condition is inconvenient and do not have places for leisure. Accordingly, they tend to migrate to developed regions, such as cities.

Fifth, compared with islands, cities have better living conditions, which is inclusive of sound public facilities, high-quality education, proper medical treatment, useful public service. Hence, whether to enjoy a better quality of life, pursue better educations for children or other things, moving to cities is a better choice.

Sixth, most islands' striplings yearn for seeing the scenery of cities, have massive ambition, and love to entertain, so cities' appeal to young people is high. As far as transport is concerned, for now, the transportation is highly developed, and the journey to cities is safe, time-saving and convenient. Accordingly, young people can migrate to cities more easily.

\subsection{Low Population Quality}

In order to find out whether the old residents are well educated and are qualified for some positions 
which require relatively higher skills, we did a random survey at various locations on the island. The following Figure 2 is the very survey whose object is the older residents who are above 60 years old.

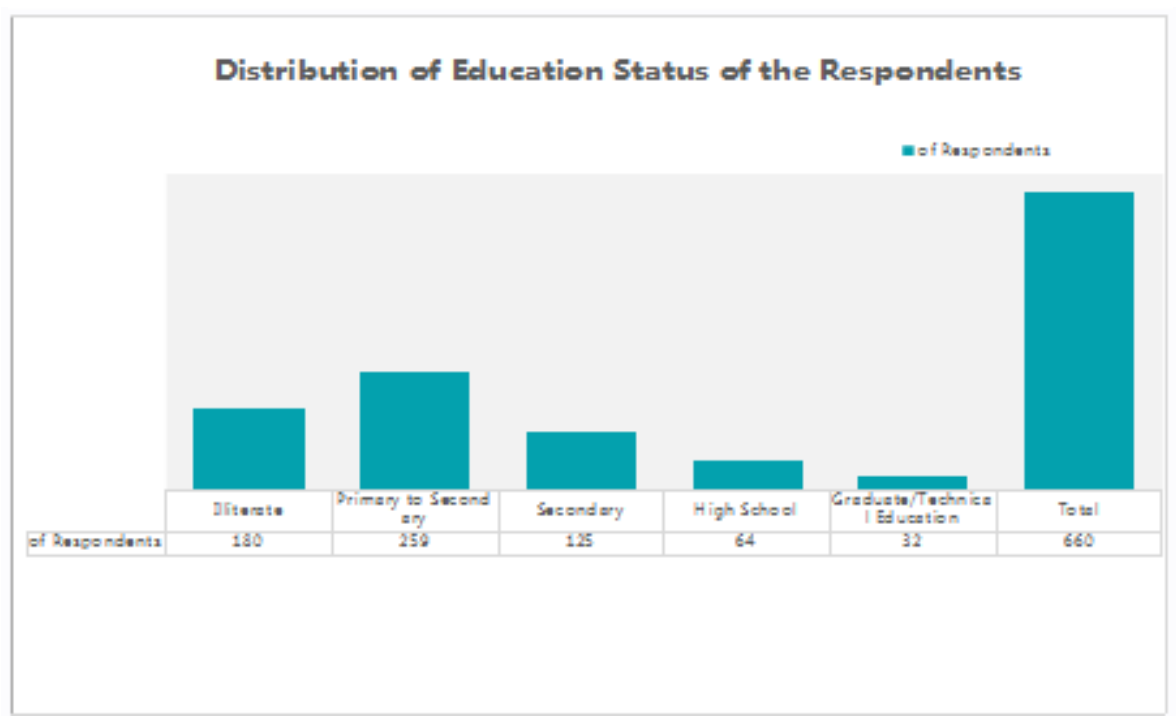

From this above table, it can be said that the respondents' literacy level from primary to upper primary accounts for $39.24 \%$, which is the highest proportion. Secondary and H.S. level literate respondents share 12.72 and 9.7 percent, respectively, whereas the graduate or respondents who received higher vocational education are $4.85 \%$. Besides, on account of the universal islands' scarce educational resources, other age groups' quality is not high likewise.

Education is an essential parameter for assessing whether the residents have enough technical skills that enhance their production efficacy and could cater to the labor market's needs. These data show that the economic value generated by other age groups and the local elderly when they go back to work is low. Hence, in the Suggestion part, the countermeasures to handle this will be given.

\subsection{The Lack of Islands' Unique Features in Tourism}

There are a lot of authoritative studies and news reports about many regions suffering from the depletion of fishery resources. This made us wonder whether Taohua Island has such a situation or not. The following Figure 3 is over the production value of each industry of Taohua Island in 20152017.

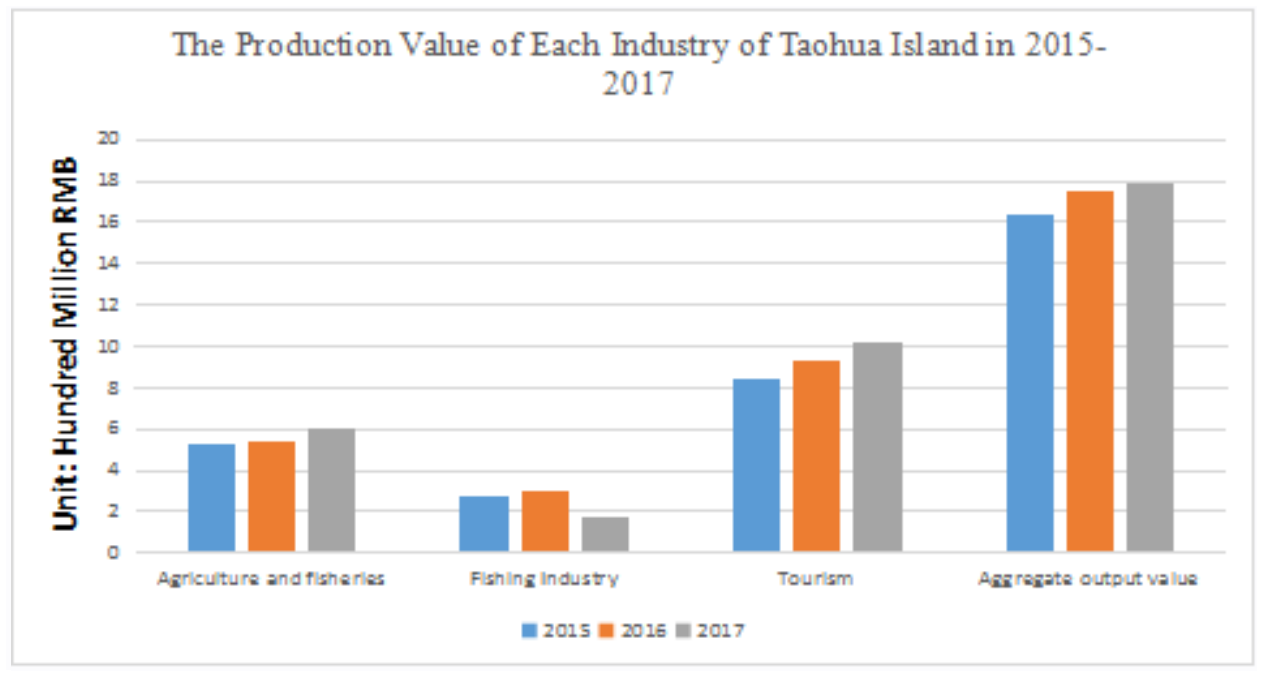

From the above table and the documents of Taohua Island, it is explicit that tourism is the leading industry of Taohua Island, and its development momentum has been spectacular. Also, because of the scales of local enterprises are small (Micro enterprises and small ones make up 66.67\%, and 33.33\% of the enterprises interviewed are medium enterprises, and most of the firms are partnership firms), their output value cannot be increased in the short run. Therefore, we should strive to develop the tourism industry. 
Culture is the soul of tourism and the distinguishing factor of different regions. Tourism culture is the source that could sustain the development of the tourism economy everlastingly. Many a renowned island has its distinctive culture, such as Maldives's islands and Hawaii. For Taohua Island, it is the Pharmacist Huang's residence in Jin Yong's novel. Nevertheless, it does not have any other attractions.

In addition to culture, islands should also have other characteristics, so that they can draw interest from not only tourists but investors.

\section{SugGeStions}

\subsection{Develop Characteristic Island}

As discussed above, tourism is the leading industry of Taohua Island and to which the distinctive local culture is paramount. To develop characteristic islands, we can adopt the following measures selectively.

Initially, some facilities should be constructed. These may include a cable car, a water park, an outdoor swimming pool, which like the unique swimming pool in Marina Bay Sands resort in Singapore. It will appear to float in the air, and it seems that people who swim in it will fall 200 meters from the sky without paying attention. Besides, a seafood restaurant harmonized with firstclass seafood and ocean-theme culture can also be constructed, and it can be decorated with fishermen paintings belong only to Zhoushan. These facilities can incontestably

In addition to that, the Fishing Village Tourism could be promoted. Fishing Village Tourism is a newly emerging tourism project which features fishing, swimming, having seafood, playing beach games, and gathering seafood on the beach at the ebb. It can attract many city visitors who want to get a taste of island life. Concerning the beach games, we need to inject money into the purchase of water sports equipment and other facilities.

Besides that, a folk music festival should be set up. Since the island became known as a place in Jinyong's kungfu novel, the music festival could have some Chinese features. In order to realize this, the performers can wear Han-style clothes and accompanied by a Chinese orchestra $\cdots$

Furthermore, a promotional video of Taohua Island should be shot. Many well-known islands, such as Bali and Dongji Isles have attracted a large number of visitors because some renowned movies are filmed there. We can invite excellent travel bloggers to take this sort of short movie.

Lastly, Taoist culture should be integrated into tourism. Taohua Island has a rich Taoist culture, and it can be an attractive point. Nonetheless, this measure is hard to implement and will be timeconsuming, so we recommend that this one be considered after the revival of Taohua Island.

\subsection{Change The Erroneous Concept to Old Citizens}

Some people mistakenly consider the elderly useless. However, most older adults, especially those relatively young, are healthy and can meet the needs of work units. Some older adults, such as former doctors, are very experienced, and even younger people cannot hold a candle to them. Hence, we should change these ideas, and this is the precondition of utilizing the elder human resources.

\subsection{Promote the Contributions of the Elderly to Economic Development}

\subsubsection{Prolong the Retirement Age}

The medical and health care system is improving day by day. The life expectancy thereupon has raised increasingly. In order to increase productivity and reduce the pension burden, people should work longer. Presently, China has introduced policies to increase the mandatory retirement age, but it may be more necessary to increase that in some places like Taohua Island because of their situations. Accordingly, the retirement age of Taohua Island should be raised as soon as possible.

\subsubsection{Promote The Re-employment of The Elderly}

In the survey of older people's re-employment worries, it found that old citizens' second-largest misgiving is a lack of employment channel. To expand the employment channel, we can set up employment platforms and job fairs specialized for old citizens. Commonplace employment platforms and job fairs tend to provide job opportunities to young people, and the jobs may not be appropriate for old ones, so the above suggestion is necessary. 
Furthermore, because the enterprises cannot absorb massive labor forces, we should support enterprises. Fishing Village Tourism has developed well in Taohua Island and can provide many jobs that do not require a great many technical skills. While older people are competent at these jobs, we can vigorously develop the Fishing Village Tourism.

\subsubsection{Enhance The Education Level of the Older People}

Since young people are apt to migrate to cities and towns, and the population outflow is nearly inevitable and irreversible, we must turn our attention to older people. For now, older people may be less educated and do not have too much energy resembling young people, but in the future, the older people participating in economic construction will be a trend.

Hence, the local government might as well appropriates more funds for the education of the elderly, with more schools for the elderly, and strengthening the monitoring of the teaching. Besides, some sorts of exciting contests can be held to motivate the senior to study hard. Besides, the island ought to strengthen the combination with neighboring universities, like Zhejiang Ocean University, which has offered e-business classes to the locals. Moreover, there are scores of older adults who are either not capable of doing manual labor or not want to do that, yet they are still wishing to continue working. Therefore, it is a must to offer transfer training to them.

\subsection{4. "Introduce Internet Population"}

Concerning the hardship of constructing infrastructure and recreational facilities over a short period, labor outflow will continue to exceed the inflow. To handle this and ensure sustainable island development, this paper introduced a concept: Internet Population, which means the population who participate in island development via the Internet. It is suggested that we use the Internet to let the people elsewhere to participate in Taohua Island's economic construction.

To achieve this, we should give priority to the development of e-commerce. The reason is that income for the local has become harder to increase mainly due to the stagnant growth of agricultural productivity, and by engaging in e-commerce, a rural household's annual income could be raised by 20.5 thousand RMB while holding other factors constant (Chen et al., 2016). Besides, e-commerce development is feasible in the local owing to that there is a particular demand on the farm products, seafood, and other products of Taohua Island, and on the island, the labor, capital, and living costs are lower. Concerning concrete measures to developing local e-commerce, we must attach importance to three aspects: education, product branding, and logistics. As for education, we should ensure that some people know how to sell goods via the Internet. Here we recommend that the cooperation between colleges and Taohua Island be strengthened. Colleges can offer courses of e-commerce for people of Taohua Island. Besides, it would be better if some e-commerce teachers or volunteers can visit the locality and teach the people there. As for the products, a brand of products should be built, and the local sellers should band together. Without doing such things, there will be too much competition, as the local sellers' goods are similar or identical. As for the logistics system, it is far from perfect in the locality. To improve it, firstly, the government might as well build platforms for enterprises and farmers, so that the enterprises can be commissioned to sell farmers' goods or purchase farmers' goods. Secondly, it is advised that the government can also try hard to make agreements with some logistics company so as to build up the logistics system with concerted effort.

Apart from e-commerce, it is also vital to organize all sorts of voluntary activities. For instance, we can organize a voluntary activity that requires volunteers to shoot promotional videos for Taohua Island and reward the volunteers whose videos are excellent. Likewise, we can organize a voluntary activity requiring volunteers to make preparations for the island's folk music festival.

The last significant tip is setting up a forum of Taohua Island. The local government can post some questions brought by local development in the forum and let the netizens to put forward some proposals. To boost the netizens' enthusiasm, we can establish an incentive system to give rewards to some people who make constructive and workable suggestions. Also, some recruitment information such as advertising for some workers of wall painting can be posted in the forum.

\section{FUTURE ASSUMPTION}

After all these research, some thoughts sprang to our mind: if we intend to develop islands rapidly and sustainably, we must endeavor to build two brands, namely the regional tourism brand and the product brand. If there is no such brands, Taohua Island cannot stand out from other islands or other tourist attractions, and neither can Taohua Island's local specialties attract legions of customers. 
Hence, we hope that in the future, there will be research which is aimed to build these two brands. We hope that this thesis can provide a new direction and a new perspective for later studies.

\subsection{Questionnaire}

\section{Older Citizen Survey}

1. What is your gender?

- Male

- Female

2. What is your age?

- Between age 55-70

- Between age 70-80

- Over 80

3. What is your main source of income?

- Working

- Retirement pension

- Relatives and friends

- Endowment insurance

- Maintenance from your children

- Minimum government subsidy

4. Are you still engage in any work?

- Yes

- No

5. What is your current job or last job?

6. If you don't work currently, how likely will you do that in the future?

- Extremely likely

- Very likely

- Somewhat likely

- Not so likely

- Not at all likely

7. If you are not working, what may be your worries as regards to continuing working?

- Lack of personal stamina

- Lack of personal marketable skills

- Lack of careers guidance received

- Narrow employment channels

- Family reasons

- The welfare package may be poor

- Enterprises may not be interested in employing older citizens

- Lack of effective legal guarantee

- Not applicable 
8. If you are working, how many years do you prepare to work?

- Less than one year

- One year to two years

- Three years to five years

- More than five years

9. What may drive you to continue working (choose all that apply)?

- Financial reasons

- Working can bring more healthier lifestyle

- Working can bring self-fulfilment and self-satisfaction

- Working is conducive to developing and maintaining friendships

- Passing on your craft to the next generation

- Not applicable

10. Do you have the following diseases(choose all that apply)?

\begin{tabular}{|c|c|}
\hline - Gout & - Anemia \\
\hline - Diabetes & - Dementia \\
\hline - Hemiplegia & - Heart disease \\
\hline - Tuberculosis & - Hypertension \\
\hline - Chronic bronchitis & - Hyperlipemia \\
\hline - Chronic renal failure & - Parkinson's disease \\
\hline $\begin{array}{ll}\text { - } & \text { Chronic } \\
\text { gastroenteritis }\end{array}$ & \\
\hline
\end{tabular}

11. How often do you often fell unwell physically or mentally in daily life?

- Frequently

- Very often

- Often

- Not quite often

- Not at all

12. Have you been hospitalized last year?

- Yes

- No

13. How do you pay for your medical expenses?

- Basic Medical Insurance System for Urban Employee

- Urban Basic Medical Insurance System

- New Rural Co-operative Medical Care System

- Rural Poverty Relief System

- Commercial medical insurance

- Pay at your own expense

14. What is the highest level of education you have attained?

- Graduate/Technical education

- High school 
- Secondary

- Primary to secondary

- Illiterate

\section{Enterprise Owner Survey}

1 . What is the nature of your firm?

- Sole Proprietorship

- Partnership

- Limited liability company

- Limited company

2. How long has your company been established?

- One to ten years

- Eleven to twenty years

- Over twenty-one years

3. How big is your business?

- Micro

- Small

- Medium-sized

- Large

4. Could you say something about your employees' education level?

5. How many people do you hire and how many older people do you hire?

6. Do you feel it difficult to hire employees?

- Yes

- No

7. What kind of employees is most hard to hire?

- Less experienced staff

- Skilled worker

- Management

- Technical staff

8. If it is difficult to recruit staff, what are the causing factors of it?

- Narrow recruitment channel

- The applicants were not qualify for the vacant position

- The applicants' ages haven't met the company's requirement

- The labour cost

- Labour dispute

- Not applicable

9. How likely is it that you will hire older adults (over 60 years old)?

- Extremely likely

- Very likely 
- Somewhat likely

- Not very likely

- Not at all likely

10. What do you think about older employees (over age 60)?

11. Facing fierce competition, have you done something to stand out from others?

12. What factors may hinder your company's growth?

13. Do you feel that the aging problems have caused inconveniences to your company?

14. What is your company's future strategy?

\section{REFERENCES}

[1] Manson, R. Lee., Reform and Support Systems for the Elderly in Developing Countries: Capturing the Second Demographic Dividend, [J]. 2006, 57 (2) :11-35

[2] XZ Jiang, Ty Liu, CW Su, China's marine economy and regional development, [J]. 2014, 50:227-237

[3] Jiaqi Qi, Hongdong Guo, China Economic Review, [J]. 2019, 53:106-127

[4] Lorna Philip, Fiona Williams, Journal of Rural Studies, [J]. 2019, 68:306-318

[5] 谷秀慧, 浅析人口老龄化对经济发展的影响 [J], China Collective Economy, 2018（05）

[6] 李建新. 中国人口结构问题 [M]. Beijing: Literature of Social Science Press， 2009

[7] 舟山市发改委. 浙江省舟山市战略性新兴产业发展现状及下步工作建议 [OB/OL].http://www. china sei.com.cn/dfldjdfggwdt/201808/t20180824_23434.htm1.2018.08. 24

[8] 杜鹏, 王武林. 论人口老龄化程度城乡差异的转变 $[J]$. Population Research, 2010 （3）

[9] 宋银山, 李否, 王光远. 京津冀人口结构变化与经济协调发展的分析研究 [J]. Money China, 2018 (08)

[10] 王启元, 陈惠, 于深. 论人口老龄化对我国产业结构的影响 [J]. New Finance Economics, 2011 (10)

\section{AUTHORS' BIOGRAPHY}

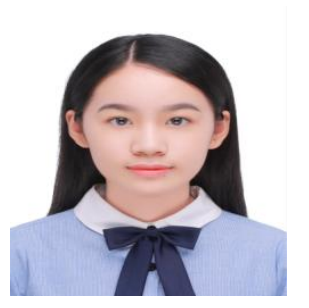

Yangyang Chen, a Business English major of Zhejiang Ocean University, Zhejiang, China.

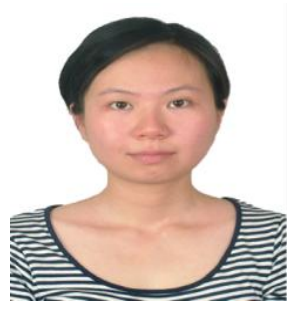

Fangjie He, a lecturer of Faculty of Foreign Languages, Zhejiang Ocean University, Zhejiang, China.

Citation: Yangyang Chen, Fangjie He. "On Ways of Developing Islands from the Perspective of Population and Islands'Special Features". International Journal of Humanities Social Sciences and Education (IJHSSE), vol. 6, no.12, 2019, pp. 124-133. doi: http://dx. doi.org/10.20431/2349-0381.0612010.

Copyright: () 2019 Authors. This is an open-access article distributed under the terms of the Creative Commons Attribution License, which permits unrestricted use, distribution, and reproduction in any medium, provided the original author and source are credited. 